Volume 5

Issue 2 Reducing Discrimination in the

Workplace

2019

\title{
Examining Why and for Whom Reflection Diversity Training Works
}

\author{
Alex P. Lindsey \\ University of Memphis \\ Eden King \\ Rice University \\ Brittney Amber \\ Indiana University - Purdue University Indianapolis \\ Isaac Sabat \\ Texas A\&M University \\ Afra S. Ahmad \\ George Mason University
}

Follow this and additional works at: https://scholarworks.bgsu.edu/pad

Part of the Human Resources Management Commons, and the Industrial and Organizational

Psychology Commons

How does access to this work benefit you? Let us know!

\section{Recommended Citation}

Lindsey, Alex P.; King, Eden; Amber, Brittney; Sabat, Isaac; and Ahmad, Afra S. (2019) "Examining Why and for Whom Reflection Diversity Training Works," Personnel Assessment and Decisions: Number 5 : Iss. 2 , Article 10.

DOI: https://doi.org/10.25035/pad.2019.02.010

Available at: https://scholarworks.bgsu.edu/pad/vol5/iss2/10

This Main Article is brought to you for free and open access by the Journals at ScholarWorks@BGSU. It has been accepted for inclusion in Personnel Assessment and Decisions by an authorized editor of ScholarWorks@BGSU. 


\title{
EXamining Why and for Whom Reflection DIVERSITY TRAINING WORKS
}

\author{
Alex P. Lindsey ${ }^{1}$, Eden King ${ }^{2}$, Brittney Amber ${ }^{3}$, Isaac Sabat ${ }^{4}$, and \\ Afra S. Ahmad ${ }^{5}$
}

\author{
1. University of Memphis \\ 2. Rice University \\ 3. Indiana University - Purdue University Indianapolis \\ 4. Texas A\&M University \\ 5. George Mason University
}

ABSTRACT

\begin{tabular}{c}
\hline KEYWORDS \\
diversity training, diversity, \\
reflection, social dominance \\
orientation, trainee \\
characteristics
\end{tabular}

\begin{abstract}
This research introduces a novel approach to diversity training by theoretically developing and empirically testing a model that considers a new training exercise aimed at improving proximal and distal pro-diversity outcomes. This new training exercise, reflection, is proposed to be effective at increasing pro-diversity attitudes and behaviors due to the promotion of one's internal motivations to respond without prejudice. Further, we test a critical trainee characteristic, social dominance orientation (SDO), as a boundary condition of our proposed effects. Results from an online experiment with two time points indicate that reflection can be an effective diversity training exercise and leads to better pro-diversity attitudes and behaviors through one's internal motivation to respond without prejudice. Social dominance orientation moderated these indirect effects, such that reflection was more effective for those high in SDO, counter to expectations. Implications of this research and future directions are discussed.
\end{abstract}

Diversity in the United States workforce has steadily increased over the past 50 years and is expected to continue into the future (Burns, Barton, \& Kerby, 2012; Toosie, 2006). The most common response by organizations to this change has been to institute diversity training programs. Indeed, approximately $68 \%$ of companies in the U.S. report having diversity initiatives in place, and diversity training is the most common of these initiatives, with $71 \%$ of those companies using diversity training specifically (Society for Human Resource Management, 2010). As a result, critical yet unanswered questions have emerged regarding why and for whom diversity training works. Unfortunately, traditional approaches to diversity training typically yield small and inconsistent effects (Bezrukova, Jehn, \& Spell, 2012). Furthermore, diversity training methods, if not framed appropriately, can actually lead to counterproductive increases in both implicit and explicit expressions of prejudice via backlash (Legault, Gutsell, \& Inzlicht, 2011).

Accordingly, this study proposes a novel strategy to enhance the positive outcomes of diversity training (see Figure 1). Specifically, we introduce a theoretically grounded intervention that requires active reflection and counterfactual thinking about past instances of observed discrimination. We identify increases in internal motivation to respond without prejudice as a key mediator in the process by which reflection affects pro-diversity attitudes and behaviors. We further stipulate that participant social dominance orientation (SDO) attenuates these effects. Given that previous research findings with regard to diversity training effectiveness have been mixed (Bezrukova et al., 2012), this search for substantive explanatory mechanisms and boundary conditions is of both scholarly and practical importance.

This work will guide future research by articulating a theory-driven diversity training activity and by explaining why and for whom reflection works. Practically speaking, this paper will offer guidance to practitioners regarding

Corresponding author:

Alex P. Lindsey

Email: Alex.Lindsey@memphis.edu 
FIGURE 1.

Theoretical Model.

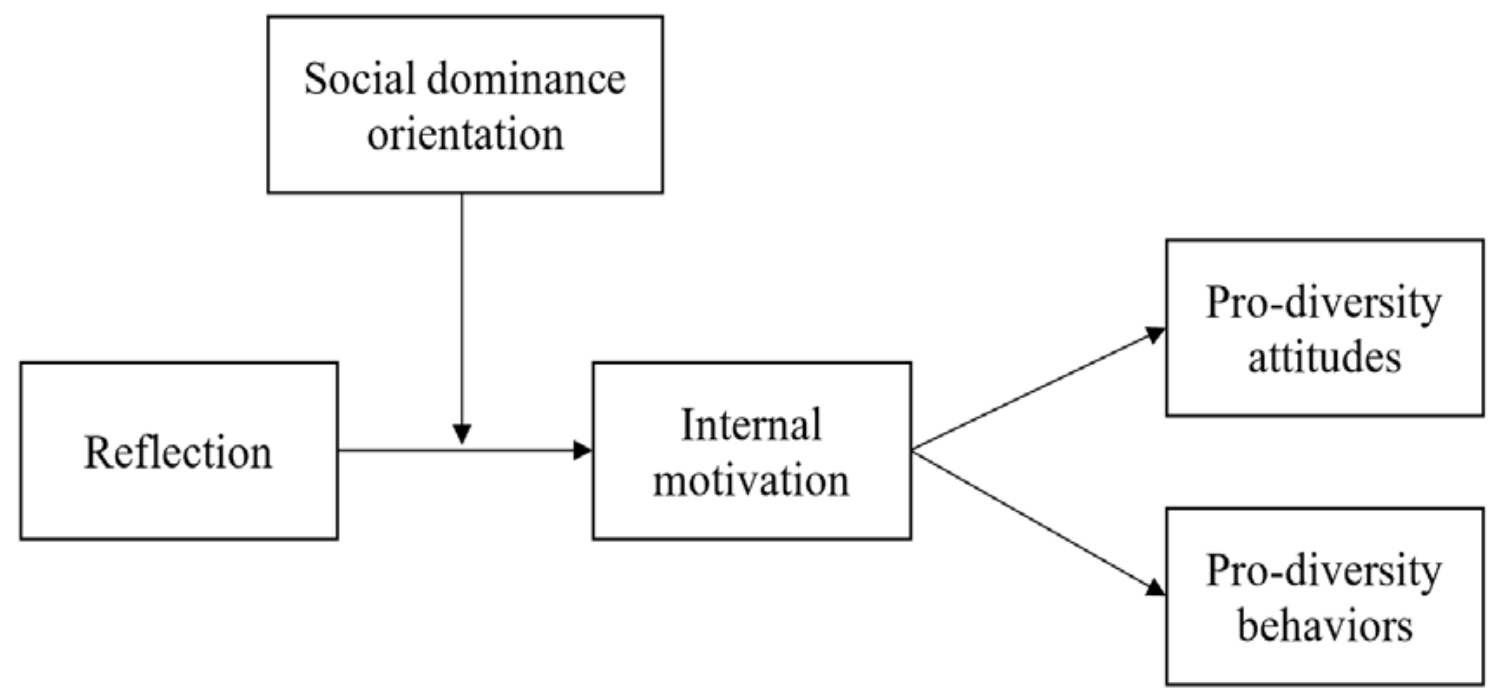

how to effectively leverage diversity training exercises, what outcomes should be measured, when those outcomes should be measured, and what individual difference variables need to be considered in order for diversity training to be maximally effective.

\section{Reflection as a Diversity Training Exercise}

Diversity training can be defined as "a distinct set of programs aimed at facilitating positive intergroup interactions, reducing prejudice and discrimination, and enhancing the skills, knowledge, and motivation of people to interact with diverse others" (Bezrukova et al., 2012, p. 208). A recent meta-analysis revealed that the most common forms of diversity training were lecture $(21 \%)$, reading $(19 \%)$, discussion (19\%), videos $(10 \%)$, and role plays $(10 \%$; Nittrouer, Hebl, \& Oswald, 2016). Further, Bezrukova and colleagues' review revealed that $91 \%$ of diversity training studies either use multiple methods of instruction or did not specify the method used (2012). Although this first piece should not be surprising given that most research concludes that multiple methods are more effective than using a single method (e.g., a lecture), using multiple methods per study may preclude us from uncovering findings regarding which activities are most beneficial. Accordingly, we introduce a theory-driven, targeted activity we call reflection and then compare this exercise to other established methods (i.e., perspective taking and goal setting) as well as a control condition.

Reflection is a learning activity that requires one to examine past experiences for purposes such as problem solving, understanding, sense making, appreciation, and/ or awareness (Roessger, 2013). More generally, reflection is seen as a critical element of learning (Rodgers, 2002), which is a key outcome of effective diversity training programs. This method of training has yet to be applied in discrimination reduction research and practice. We assert that a reflection activity can be implemented in the diversity training domain by encouraging individuals to think of past experiences regarding prejudice, review what happened, how they responded, what they wished they would have done differently in the situation, and what they hope to do differently in the future. Previous research on bias awareness shows a similar process, that learning about and acknowledging one's own biases is a critical, important step in changing behavior (Monteith, Mark, \& Ashburn-Nardo, 2010; Perry, Murphy, \& Dovidio, 2015). Lindh and Thorgren (2016) assert that through systematic reflection on thoughts, emotions, and behaviors relative to lived experiences, people learn how to self-regulate their behavior. Experimental research has found that recognizing discrepancies between how one responded in prior racial experiences and how one wished they had responded can produce self-directed negative affect and self-regulation in the future (Monteith, Mark, \& Ashburn-Nardo, 2010). Thus, reflective thinking as a diversity intervention method should similarly facilitate self-directed thoughts and challenge one's cognitions, and lead to improvements in pro-diversity attitudes and behaviors. Specifically, we propose that this happens 
by increasing one's motivations to be unprejudiced, thereby improving pro-diversity attitudes and behaviors.

\section{Internal Motivation as an Explanatory Mechanism of Reflection Effectiveness}

Improving individuals' motivation to successfully interact with differing others is listed as a key goal and outcome in the definition of diversity training provided by Bezrukova and colleagues (2012). Internal motivation to respond without prejudice can be defined as an inherent, value-based desire to suppress expressions of prejudice (Plant \& Devine, 1998). This can be contrasted with external motivation to respond without prejudice, which can be defined as a context-dependent desire to suppress prejudice based on social desirability (Plant \& Devine, 1998). Promoting external motivation to respond without prejudice can counterintuitively increase expressions of prejudice (e.g., Legault et al., 2011) and thus may not be as effective in promoting long-lasting diversity-related outcomes when compared to internal motivation to respond without prejudice.

An individual who participates in a reflection diversity training activity and thereby critically examines their own past diversity-relevant attitudes and behaviors should theoretically be more internally motivated to respond more pro-socially in the future. Theory regarding the self-regulation of prejudice posits that when individuals perceive or recognize a discrepancy between egalitarian goals and nonegalitarian or prejudiced thoughts and behaviors, low-prejudiced individuals "(a) respond by interrupting their prejudiced behavior (and/or they will display a compensatory response), (b) experience feelings of guilt, and (c) reflect on their prejudiced behavior" (Perry, Murphy, \& Dovidio, 2015, p.65). We propose that a reflection diversity training activity promotes internal motivation to be non-prejudiced by facilitating these same three actions for everyone, not just those with intrinsic egalitarian goals. Thus, a reflection activity can increase one's internal motivation to respond without prejudice rather than only work for someone who already possess this internal motivation. Indeed, previous research has shown that diversity training, when properly framed, can lead to an increase in intrinsic motivation to respond without prejudice (Legault et al., 2011). In turn, this internal motivation to respond without prejudice should improve diversity-related attitudes and behaviors via egalitarian predispositions. Importantly, internal motivation to respond without prejudice has been shown to be predictive of positive diversity-related attitudes in general (e.g., Ratcliff, Lassiter, Markman, \& Snyder, 2006). More specifically in the context of diversity training, internal motivation to respond without prejudice has been shown to partially mediate the relationship between a perspective taking diversity training activity (an activity that shares some similarities with reflection) and pro-diversity attitudes and behaviors (Lindsey, King, Hebl, \& Levine, 2015). Thus, we would hope to extend these findings and ideas to our new reflection exercise.

Hypothesis 1: Internal motivation to respond without prejudice will partially mediate the relationship between reflection and pro-diversity attitudes and behaviors.

\section{Social Dominance Orientation as a Moderator of Diver- sity Training Effectiveness}

Social dominance theory (Sidanius, 1993; Sidanius \& Pratto, 1999) is grounded in the notion that societies are typically organized in group-based social hierarchies. Specifically, this theory suggests that intergroup conflict represents a manifestation of these group-based hierarchies. Group-based beliefs (such as ideologies involving meritocracies and group dominance) legitimize prejudiced attitudes and discriminatory treatment, serving to perpetuate social inequalities over time. This theory points to an important individual difference trainee characteristic that likely influences the effectiveness of diversity training initiatives: "a general attitudinal orientation toward intergroup relations, reflecting whether one generally prefers such relations to be equal, versus hierarchical," social dominance orientation (SDO; Pratto, Sidanius, Stallworth, \& Malle, 1994, p. 742). Studies have shown that SDO is negatively related to other variables that are known to impact diversity training outcomes, such as empathy, tolerance, and altruism (Pratto et al., 1994). Perhaps most importantly, SDO is associated with prejudicial attitudes and behaviors. For example, White applicants who were high in SDO viewed diverse organizations as less attractive when compared to those who were low in SDO (Umphress, Smith-Crowe, Brief, Dietz, \& Watkins, 2007). Furthermore, individuals who were higher in SDO expressed more negative attitudes toward low status group members based on race and gender when compared to individuals lower in SDO (Umphress, Simmons, Boswell, \& Triana, 2008). These findings serve to demonstrate that SDO is inversely associated with pro-diversity attitudes, which leads us to reason that trainees who are lower in SDO may be more responsive to reflection when compared to those who are higher in SDO. Thus, we predict that reflection may result in null (or even negative) effects on diversity training outcomes for those high in SDO.

Hypothesis 2: Trainee SDO will moderate the indirect effect of reflection on pro-diversity attitudes and behaviors via internal motivation to respond without prejudice, such that reflection will be more effective for those lower in SDO. 


\section{METHOD}

\section{Participants and Procedure}

Participants were recruited via Amazon's Mechanical Turk and paid $\$ 0.25$ per completed survey. Participants were deemed eligible for this study if they were at least 18 years old, resided in the United States, and worked at least 30 hours per week. The study was advertised as being about workplace experiences in general. The original sample consisted of 246 employees working at least 30 hours per week. The sample was $62 \%$ male, $35 \%$ White, $52 \%$ Asian or Asian-American, 6\% Black, 3\% Hispanic, and $4 \%$ were of another ethnicity. This is a rather high proportion of Asian or Asian-Americans compared to most U.S. samples; however, these participants did all reside in the U.S. The sample had an average age of 33 years old and an average tenure of 7 years with their organization. Of this original sample, 147 participants completed both time points and were used in the current analyses for a retention rate of $60 \%$. This sample that completed the study was very similar demographically to the original sample. Indeed, this sample was $64 \%$ male, $37 \%$ White, $52 \%$ Asian or Asian-American, 3\% Black, 3\% Hispanic, and 5\% were of another ethnicity. This sample had an average age of 33 years old and an average tenure of 7 years at their organization. A wide range of occupations were represented in our sample, the most prevalent being administrative and support services $(14.3 \%)$, educational services $(13.6 \%)$, finance and insurance $(9.5 \%)$, information $(8.8 \%)$, and manufacturing $(8.8 \%)$. This final sample also passed two attention checks (e.g., "Select 'Strongly Agree' if you are reading this question) and a manipulation check (i.e., the first author read their diversity training activities to ensure they participated as instructed). These attention and manipulation checks were included to help ensure quality of data (Porter, Outlaw, Gale, \& Cho, 2018). We conducted a logistic regression analysis to examine whether any of the Time 1 variables could predict whether a participant completed the study or not. This analysis yielded no significant results (all $p \mathrm{~s}>.20$ ).

This study involved two time points. First, participants were assigned to one of four diversity-training conditions: reflection, perspective taking, goal setting, or a control condition. At the conclusion of this training exercise, participants completed the measures of diversity-related motivations and social dominance orientation. A few days later, participants completed the second survey containing measures of pro-diversity attitudes and behaviors.

\section{Materials}

Diversity training method. Participants in the reflection condition were asked to reflect on a time when they witnessed prejudicial behavior at work. With this memory in mind, participants were then asked to write a few sentences about what happened, how they responded, and what they wished they would have done differently in the situation (see Appendix A for the full activity). Those participating in the goal setting diversity training were asked to personally set specific, challenging, and attainable goals related to diversity (adapted from Lindsey et al., 2015). Those participating in the perspective taking diversity training were asked to consider the challenges faced by marginalized groups. With these challenges in mind, these participants were then asked to write a short narrative about what a typical day would be like for a member of a marginalized group to gain a better understanding of the challenges they face (adapted from Lindsey et al., 2015). Finally, participants in the control condition were simply asked to write about their day prior to the study. For the sake of consistency, each exercise required participants to write a total of four to five sentences.

Pro-diversity attitudes. To measure pro-diversity attitudes, we used a 10-item scale adapted from Stanley (1996). This scale was designed to capture self-reported attitudes toward pluralism and diversity in the workplace and educational environments (sample item: "Each minority culture has something positive to contribute to American society"; $\alpha=.94$ ). This scale utilized a Likert response scale ranging from 1 (strongly disagree) to 7 (strongly agree).

Pro-diversity behaviors. A 10-item scale developed by Linnehan, Chrobot-Mason, and Konrad (2006) was used to measure diversity-related behaviors. This scale was designed to capture intentions to engage in supportive behaviors toward diverse populations and asked participants to rate their likelihood from 1 (unlikely) to 7 (very likely) of engaging in pro-diversity behaviors over the next month (sample item: "Point out if others use language that may be offensive to members of certain demographic groups"; $\alpha=$ $.93)$.

Internal Motivation to Respond without Prejudice. An adapted version of a 5-item scale developed by Plant and Devine (1998) was used to measure internal motivation to respond without prejudice (sample item: "I attempt to act in non-prejudiced ways toward minorities because it is personally important to me"; $\alpha=.87$ ). This scale uses Likert ratings from 1 (strongly disagree) to 7 (strongly agree).

Social dominance orientation (SDO). SDO was measured using an adapted 8-item scale developed by Pratto and colleagues (1994). We utilized a Likert response scale ranging from 1 (strongly disagree) to 7 (strongly agree). A sample item from this scale is "Sometimes other groups must be kept in their place" $(\alpha=.96)$.

\section{RESULTS}

Hypothesis 1 predicted that internal motivation to respond without prejudice would mediate the relationship between reflection and distal outcomes. To test this hypothesis, we used regression-based path analysis, regressing each 
endogenous variable onto its direct determinants. Specifically, we used macros developed by Hayes (2013) designed for testing mediation models using regression analysis and bootstrapping techniques. Distal training outcomes of attitudes and behaviors were regressed onto the mediator (internal motivation to respond without prejudice), which we in turn regressed onto three dummy coded variables (one indicator for each experimental condition) with the control condition serving as the uncoded group.

The model predicting attitudes revealed an insignificant indirect effect of the reflection activity through internal motivation to respond without prejudice (coefficient $=$ $0.23,95 \%$ CI $[-0.02,0.48])$. Similarly, the model predicting behaviors revealed an insignificant indirect effect of the reflection activity through internal motivation to respond without prejudice $($ coefficient $=0.22,95 \%$ CI $[-0.02,0.48]$ ). Collectively, these results do not support Hypothesis 1.

One reason that we may have failed to detect significant indirect effects is that these effects may vary across levels of our moderator. Indeed, Hypothesis 2 proposed that the indirect effects of reflection may vary depending on participant SDO, with training being less effective for those who are high on SDO. To test this hypothesis, we added trainee SDO as first stage moderator to the indirect effects examined above. We then used the same macro to analyze conditional indirect effects. Results showed that the indirect effect of reflection on attitudes through internal motivation varied across levels of SDO. Specifically, this indirect effect was significant for participants high in SDO (coefficient $=$ $.52,95 \%$ CI $[0.17,0.95])$ but insignificant for participants low in SDO (coefficient $=-.05,95 \%$ CI [-0.46, 0.35]). Similarly, results showed that the indirect effect of reflection on behaviors through internal motivation varied across levels of SDO. Specifically, this indirect effect was significant for participants high in SDO (coefficient $=0.51,95 \%$ CI [0.16, 0.91]) but insignificant for participants low in SDO (coefficient $=-.05,95 \%$ CI $[-0.46,0.36])$. Probing these findings further, results revealed a significant interaction between reflection and SDO in predicting internal motivation $(b$ $=.27, p<.05$ ). See Figure 2 for a plot of this interaction. Counter to expectations, reflection and SDO interacted such that reflection promoted higher levels of internal motivation for those who were higher in SDO, which in turn promoted more positive diversity-related attitudes $(b=.48, p<.01)$ and behaviors $(b=.47, p<.01)$. Collectively, these results do not support Hypothesis 2. However, SDO did appear to alter indirect effects in the opposite direction as was predicted.

FIGURE 2.

Plotted Interaction Between Reflection and Social Dominance Orientation in Predicting Internal Motivation to Respond Without Prejudice.

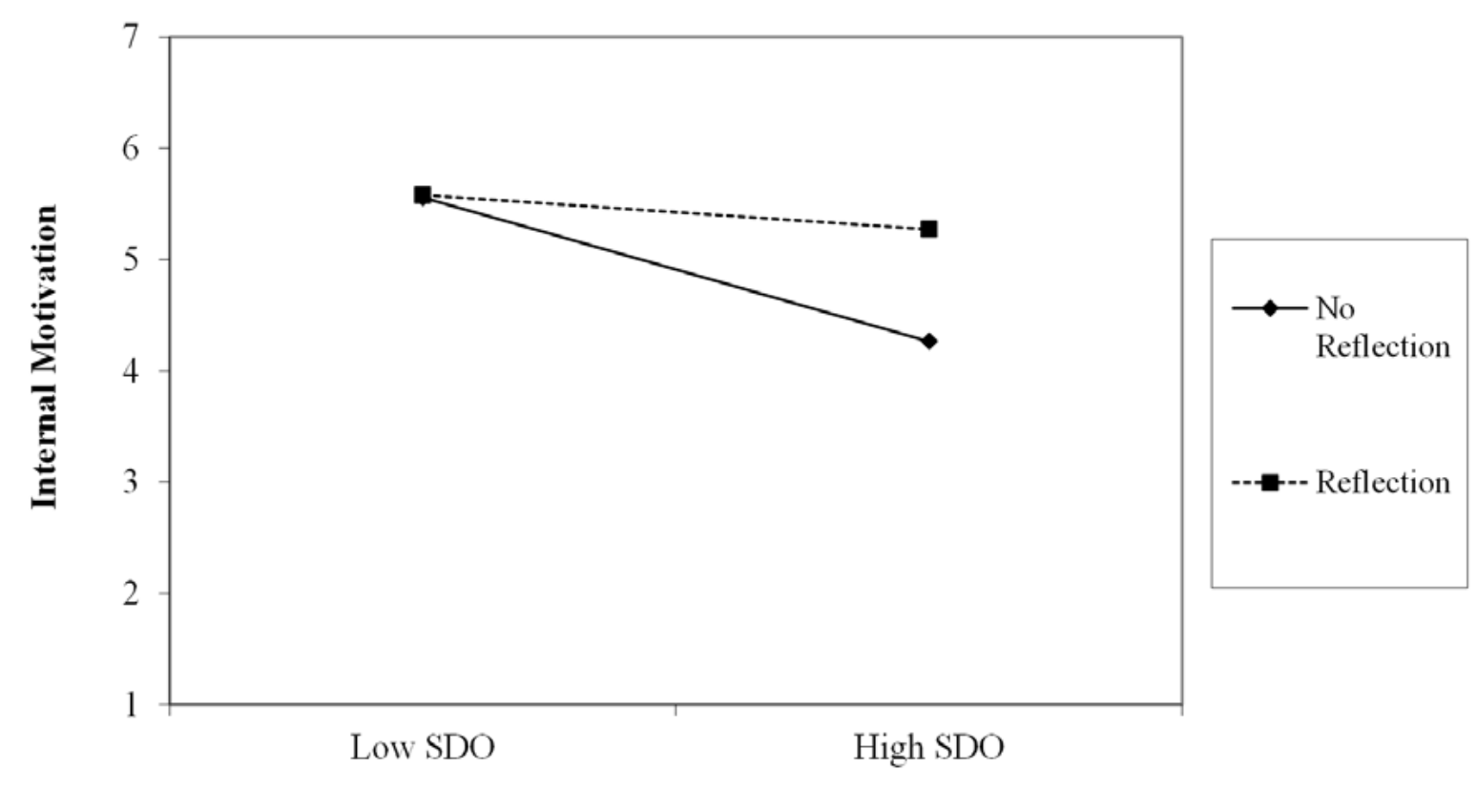




\section{DISCUSSION}

This study sought to understand why and for whom reflection may lead to pro-diversity attitudes and behaviors. Our results also indicate that SDO is an important individual difference characteristic to consider in predicting when reflection is mostly likely to lead to beneficial outcomes. Surprisingly, we found that the reflection activity may be an especially effective way to reach people who are particularly resistant to diversity training exercises. Indeed, counter to our initial expectations, moderated mediation results revealed that reflection was effective in promoting internal motivation to respond without prejudice for trainees who were high in SDO, which in turn had beneficial effects on diversity-related attitudes and behaviors. One reason reflection may be a uniquely effective activity for individuals relatively high in SDO is that it does not ask one to be other focused, but instead is self-focused, thereby increasing internal motivation. That is, power and authority are both strongly related to SDO (Ho et al., 2015), thus individual high in SDO may respond better to reflection as a diversity training activity as it allows themselves to be the one in power or the one with authority rather than an instructor or another individual. Thus, this reflection activity may be beneficial by being purely self-focused, giving these individuals sole power to make the decision to be more egalitarian. Given recent research showing that individuals who are high in SDO may be in most need of training but may also be most resistant to it (e.g., Membere, King, Kravitz, \& Lindsey, 2016; Sabat et al., 2016), these are important findings to consider for diversity training scholars and practitioners. Our results also indicate that internal motivation to respond without prejudice may be an important explanatory mechanism to consider for reflection and diversity training more generally, which replicates previous research (Lindsey et al., 2015).

\section{Theoretical and Practical Implications}

Our findings present a number of theoretical and practical implications for scholars and practitioners to consider. First, reflection may be an effective addition to diversity training programs, especially when trainees may be resistant to training. Second, the finding that the reflection diversity training activity only produced beneficial effects when the proximal mediator of internal motivation to respond without prejudice was considered supports the notion that some outcomes (i.e., motivations) of diversity training can be measured immediately after training occurs, whereas others might require a time lag before effects will be observed. Thus, scholars and practitioners may want to allow for a sufficient time lag before measuring distal outcomes such as pro-diversity attitudes and behaviors. More broadly, these findings indicate that the role of time may need to be more explicitly included and stipulated in models of diversity training effectiveness. Third and finally, given our findings regarding trainee characteristics, diversity training practitioners may want to consider measuring individual differences like SDO before selecting the training activity that is most likely to be beneficial for a given group of trainees.

\section{Limitations}

Although this study has a number of strengths, it also has several limitations that should be addressed in future work. First, our reflection diversity training activity was rather short, requiring participants to only write four to five sentences. On one hand, this lessens our external validity as this training activity was not as long as we might expect in actual organizations; on the other hand, this suggests that our effect sizes are conservative and might be stronger if employed as a part of a broader diversity initiative. This also provides an explanation for some of our insignificant effects. Indeed, it is not ideal that the diversity training activities were not paired with basic diversity training (e.g., a lecture), as would typically be done in a live organization. To promote generalizability, future studies should seek to replicate and extend these findings by pairing diversity training activities with foundational diversity training in a live organization. A corresponding strength of this study is the employment of a true control group, which is often not possible or practical when utilizing field study designs. Additionally, seminal reviews of diversity training programs (e.g., Bezrukova et al., 2012; Kalev, Dobbin, \& Kelly, 2006; Kulik \& Roberson, 2008) have concluded that the addition of a standard diversity training programs would not necessarily enhance, and in some cases may have even hindered, our observed effects. Second, although it is a strength of this study that we had multiple measurement time points, future work should examine a greater number of time points over a larger timespan to more effectively analyze when specific mediators and more distal outcomes of diversity training are affected by these activities. Relatedly, it is a limitation that we did not measure our outcome variables (i.e., motivation, attitudes, and behaviors) at both time points. Doing so would have allowed to assess for change in these variables and control for individual differences in diversity training outcomes prior to the study. However, the fact that we used random assignment should partially assuage these concerns as the various diversity-related predispositions should be evenly distributed across our experimental and control conditions. Third and finally, there was a considerable amount of attrition associated with our sample. However, we have no reason to believe this attrition systematically affected results in any way. Indeed, follow-up analyses revealed that none of the Time 1 variables significantly predicted study completion. 


\section{Future Directions}

This paper provides a variety of avenues for future research directions. First, future research should investigate other potentially relevant individual difference characteristics and how they might affect the relative effectiveness of various diversity training activities. Indeed, Bezrukova and colleagues' (2012) seminal review of diversity training programs revealed that only 22 studies had examined trainee characteristics and how they affect diversity training programs, with 17 of those studies limiting their examination of individual differences to demographic characteristics. Thus, with only five studies (and perhaps a few more in recent years) examining how substantive trainee characteristics might moderate the effectiveness of training exercises, this seems like a fruitful area for future research. For example, researchers could begin to address and understand how a participants' standing on the Big Five personality traits might alter how they respond to various diversity initiatives in the workplace. Second, given our results regarding the effectiveness of reflection for individuals high in SDO, future research may examine if such a reflection activity is similarly effective at reaching other individuals who are more resistant to different forms of diversity training. Additionally, future research could explore other possible mechanisms beyond internal motivation that help explain why self-reflection may facilitate pro-diversity attitudes and behaviors for individuals high in SDO.

\section{Conclusion}

The current study provides evidence regarding the effectiveness of a novel diversity training exercise. Specifically, we found that the proposed reflection exercise leads to improved diversity related attitudes and behaviors through increased internal motivations to respond without prejudice. Although this reflection activity was most successful overall, we showed that diversity trainers may need to consider the levels of SDO of the individuals in their sample before deciding which training method to use. Additionally, more proximal outcomes and mediators of diversity training exercises may need to be measured and considered at appropriate time intervals to uncover previously masked effects. These findings provide partial support for our theoretical model in that internal motivation to respond without prejudice served as explanatory mechanisms, and SDO served as a moderator of the effectiveness of the reflection diversity training activity. Appealing to individuals who may be resistant to training or who are likely to be successful with a given activity while measuring the processes that give rise to pro-social change appears to be a promising avenue for future research and practice.

\section{REFERENCES}

Bezrukova, K., Jehn, K. A., \& Spell, C. S. (2012). Reviewing diversity training: Where we have been and where we should go. Academy of Management Learning \& Education, 11, 207227.

Burns, C., Barton, K., \& Kerby, S. (2012). The state of diversity in today's workforce. Center for American Progress. Retrieved from https://www.americanprogress.org/issues/economy/ reports/2012/07/12/11938/the-state-of-diversity-in-todaysworkforce/

Hayes, A. F. (2013). Introduction to mediation, moderation, and conditional process analysis: A regression-based approach. New York, NY: The Guilford Press.

Ho, A. K., Sidanius, J., Kteily, N., Sheehy-Skeffington, J., Pratto, F., Henkel, K. E., Foels, R., \& Stewart, A. L. (2015). The nature of social dominance orientation: Theorizing and measuring preferences for intergroup inequality using the new SDO7 scale. Journal of Personality and Social Psychology, 109(6), 1003-1028.

Kalev, A., Dobbin, F., \& Kelly, E. (2006). Best practices or best guesses? Assessing the efficacy of corporate affirmative action and diversity policies. American sociological review, 71(4), 589-617.

Kulik, C. T., \& Roberson, L. (2008). 8 Diversity initiative effectiveness: What organizations can (and cannot) expect from diversity recruitment, diversity training, and formal mentoring programs. Diversity at work, 265-317.

Legault, L., Gutsell, J. N., \& Inzlicht, M. (2011). Ironic effects of antiprejudice messages how motivational interventions can reduce (but also increase) prejudice. Psychological Science, 22, 1472-1477.

Lindh, I., \& Thorgren, S. (2016). Critical event recognition: An extended view of reflective learning. Management Learning, 47(5), 525-542.

Lindsey, A., King, E., Hebl, M., \& Levine, N. (2015). The impact of method, motivation, and empathy on diversity training effectiveness. Journal of Business and Psychology, 30, 605617.

Linnehan, F., Chrobot-Mason, D., \& Konrad, A. M. (2006). Diversity attitudes and norms: The role of ethnic identity and relational demography. Journal of Organizational Behavior, 27, 419-442.

Membere, A., King, E., Kravitz, D., \& Lindsey, A. (2016, April). Building diversity training programs that appeal to resistant trainees. Poster presented at the 31st Annual Conference of the Society for Industrial Organizational Psychology, Anaheim, CA.

Monteith, M. J., Mark, A. Y., \& Ashburn-Nardo, L. (2010). The self-regulation of prejudice: Toward understanding its lived character. Group Processes \& Intergroup Relations, 13, 183200.

Nittrouer, C., Hebl, M., \& Oswald, F. (2016, April). In A. Lindsey and V. Gilrane (Chairs), Novel approaches for enhancing diversity training effectiveness in the workplace. Symposium 
conducted at the 31st Annual Conference for the Society for Industrial Organizational Psychology, Anaheim, CA.

Perry, S. P., Murphy, M. C., \& Dovidio, J. F. (2015). Modern prejudice: Subtle, but unconscious? The role of bias awareness in Whites' perceptions of personal and other's biases. Journal of Experimental Social Psychology, 61, 64-78.

Plant, E. A., \& Devine, P. G. (1998). Internal and external motivation to respond without prejudice. Journal of Personality and Social Psychology, 75, 811-832.

Porter, C. O. L. H., Outlaw, R., Gale, J. P., \& Cho, T. S. (2018). The use of online panel data in management research: A review and recommendations. Journal of Management, 45(1), 319-344.

Pratto, F., Sidanius, J., Stallworth, L.M., \& Malle, B.F. (1994). Social dominance orientation: A personality variable predicting social and political attitudes. Journal of Personality and Social Psychology, 67, 741-763.

Ratcliff, J. J., Lassiter, G. D., Markman, K. D., \& Snyder, C. J. (2006). Gender differences in attitudes toward gay men and lesbians: The role of motivation to respond without prejudice. Personality and Social Psychology Bulletin, 32, 1325-1338.

Rodgers, C. (2002). Defining reflection: Another look at John Dewey and reflective thinking. Teachers College Record, 104(4), 842-866.

Roessger, K. M. (2013). But does it work? Reflective activities, learning outcomes and instrumental learning in continuing professional development. Journal of Education and Work, 28(1), 83-105.

Sabat, I., Bolunmez, B., King, E., Lindsey, A., Gulick, L., \& Choos, L. (2016, April). Recognizing bias about bias can improve diversity training effectiveness. In A. Lindsey and V. Gilrane (Chairs), Novel approaches for enhancing diversity training effectiveness in the workplace. Symposium presented at the 31st Annual Conference for the Society for Industrial Organizational Psychology, Anaheim, CA.

Sidanius, J. (1993). The psychology of group conflict and the dynamics of oppression: A social dominance perspective. In S. lyengar W. McGuire (Eds.), Explorations in political psychology (pp. 183-219). Durham, NC: Duke University Press.

Sidanius, J. \& Pratto, F. (1999). Social dominance: An intergroup theory of social hierarchy and oppression. New York, NY: Cambridge University Press.

Society for Human Resource Management. (2010). SHRM workplace diversity practices: How has diversity and inclusion changed over time? Available at https://blog.shrm. org/workplace/shrm-poll-workplace-diversity-practices-how-has-diversity-and-inclusion-cha

Stanley, L. S. (1996). The development and validation of an instrument to assess attitudes toward cultural diversity and pluralism among preservice physical educators. Educational and Psychological Measurement, 56, 891-897.

Toosie, M. (2006). A new look at long term labor force projections to 2050. Monthly Labor Review, November, 19-39.

Umphress, E., Simmons, A., Boswell, W., \& Triana, M. (2008). Managing discrimination in selection: The impact of directives from an authority and social dominance orientation. Journal of Applied Psychology, 93, 982-993.
Umphress, E. E., Smith-Crowe, K., Brief, A. P., Dietz, J., \& Watkins, M. B. (2007). When birds of a feather flock together and when they do not: Status composition, social dominance orientation, and organizational attractiveness. Journal of Applied Psychology, 92, 396-409.

RECEIVED 05/31/18 ACCEPTED 02/06/19 


\section{Appendix A}

\section{Diversity Training Activity - Reflection}

We have all had diversity-related experiences in which we wish we would have behaved differently than we actually did. For example, people sometimes "laugh off" inappropriate and insensitive jokes based on diversity-related factors (e.g., race, ethnicity, gender, age, spiritual beliefs, sexuality, class, income, etc.) before later wishing they had spoken up or done something to combat prejudice. For this exercise, we would like you to write about such an experience (preferably a workplace experience). Specifically, please write four to five sentences below about a time when you witnessed prejudice or discrimination at work. What happened? How did you respond? What do you wish you would have done differently? 